\title{
Erratum zu: Wirtschaftlichkeitsanalyse eines virtuellen Minutenreserve-Kraftwerks aus dezentralen Klein-Kraft-Wärme-Kopplungsanlagen
}

Dirk Hinkel • Eva Marie Kurscheid • Margarit Miluchev

Online publiziert: 22. April 2010

(C) Vieweg+Teubner 2010

Erratum zu: Z Energiewirtsch (2009) 33:127-134

DOI 10.1007/s12398-009-0015-Z

In der Online-HTML-Version ist der Nachname des ersten Autors leider fehlerhaft veröffentlicht worden.

Der korrekte Name lautet Hinkel, nicht Hinke.

Die Online-Version des Original-Artikels ist zu finden unter doi:10.1007/s12398-009-0015-z.

Prof. Dr. D. Hinkel ( $\varangle)$

Betriebswirtschaftslehre und Controlling, Fachbereich

Wirtschaftsingenieurwesen, FH OOW, Studienort Wilhelmshaven,

Friedrich-Paffrath-Str. 101, 26389 Wilhelmshaven, Deutschland

e-mail: dirk.hinkel@fh-oow.de

Dipl.-Ing. E.M. Kurscheid · Dipl. Wirt.-Ing. M. Miluchev

TU Chemnitz, Chemnitz, Deutschland 